\title{
Scope and limitations of the dual-gold-catalysed hydrophenoxylation of alkynes
}

\author{
Adrián Gómez-Suárez ${ }^{1}$, Yoshihiro Oonishi ${ }^{1,2}$, Anthony R. Martin ${ }^{1,3}$ \\ and Steven P. Nolan ${ }^{*}, 5$
}

\section{Full Research Paper}

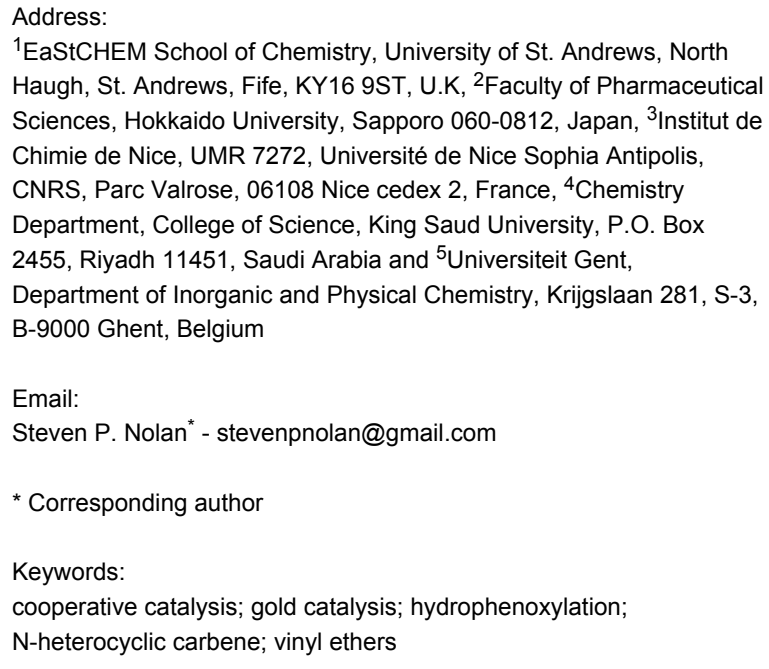

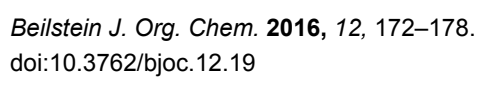

\begin{abstract}
Due to the synthetic advantages presented by the dual-gold-catalysed hydrophenoxylation of alkynes, a thorough study of this reaction was carried out in order to fully define the scope and limitations of the methodology. The protocol tolerates a wide range of functional groups, such as nitriles, ketones, esters, aldehydes, ketals, naphthyls, allyls or polyphenols, in a milder and more efficient manner than the previously reported methodologies. We have also identified that while we are able to use highly steric hindered phenols, small changes on the steric bulk of the alkynes have a dramatic effect on the reactivity. More importantly, we have observed that the use of substrates that facilitate the formation of diaurated species such as gem-diaurated or $\sigma, \pi$ digold-acetylide species, hinder the catalytic activity. Moreover, we have identified that the use of directing groups in unsymmetrical alkynes can help to achieve high regioselectivity in the hydrophenoxylation.
\end{abstract}

\section{Introduction}

During the last 30 years, N-heterocyclic carbenes (NHCs) have evolved from mere curiosities to one of the most powerful tools within the synthetic chemist's arsenal [1]. Due to their unique steric and electronic properties [2-6], NHCs are nowadays used in a myriad of chemical processes, for example as catalysts in organocatalysed reactions [7-9], or as ligands in transition metal 
and main-group chemistry [10-13]. We have been interested in exploring the use of NHC ligands in transition metal complexes for the development of highly active and well-defined catalysts. One of our main interests during the last decade has been to study the use of gold-NHC species as powerful catalysts for the construction of valuable organic molecules via the construction of $\mathrm{C}-\mathrm{C}$ or $\mathrm{C}-\mathrm{O}$ bonds [14-23]. In this regard, we have recently reported the use of $\left[\{\mathrm{Au}(\mathrm{NHC})\}_{2}(\mu-\mathrm{OH})\right]\left[\mathrm{BF}_{4}\right]$ species as dualactivation catalysts for the hydrophenoxylation of alkynes $[24,25]$. This transformation proceeds through the interaction of the gold centres with both the phenol and the alkyne motifs, thus generating a synergistic effect that produces unique catalytic activity (Scheme 1) [24,25]. In addition, this reaction is highly stereoselective and only the $Z$-isomer was observed, regardless of the substrate used.

This new, dual-catalysed methodology presents several advantages over previously reported protocols [26,27], such as milder reaction conditions or the use of lower catalyst loading. Therefore, encouraged by our preliminary studies [24], and the potential applications of the vinyl ether derivatives $\mathbf{3}$ as synthetic building blocks [28], we decided to further explore the scope and limitations of the dual-gold-catalysed hydrophenoxylation of alkynes. With this study, we sought to answer the following questions: what is the functional group tolerance of our transformation? How do steric and electronic factors affect both reaction partners? Can regioselectivity be achieved for the addition of phenols to unsymmetrical alkynes?

\section{Results and Discussion}

\section{Functional group tolerance}

We commenced our studies by assessing the functional group tolerance of the methodology (Scheme 2). With that aim we reacted diphenylacetylene (1a) with several phenols, 2a-o, in toluene, using $0.5 \mathrm{~mol} \%$ of $\left[\{\mathrm{Au}(\mathrm{IPr})\}_{2}(\mu-\mathrm{OH})\right]\left[\mathrm{BF}_{4}\right](\mathrm{IPr}=$ 1,3-bis(2,6-diisopropylphenyl)imidazol-2-ylidene) as the catalyst. Functional groups such as nitriles (3aa), ketones (3ab), esters (3ac), aldehydes (3ad), acetals (3ae) and naphthyls (3af) were well tolerated and the corresponding vinyl ethers were obtained in moderate to high yields (50-98\%). On the contrary, the use of azide (3ag) or boronic ester (3ah) functionalities did not afford the desired products [29]. The latter case can be explained due to formation of the corresponding gem-diaurated aryl species, by reaction of catalyst $\left[\{\mathrm{Au}(\mathrm{IPr})\}_{2}(\mu-\mathrm{OH})\right]\left[\mathrm{BF}_{4}\right]$ with the boronic ester [30], thus inhibiting the catalytic activity. The electronic properties of the phenol were also examined. If the electron density on the phenol is decreased, its nucleophilicity decreases and an increase in catalyst loading is needed in order to maintain relatively short reaction times (3ai and 3al) [31]. The steric hindrance on the phenol was studied next. Increasing it, with either allyl (3am) or tert-butyl (3an) groups on the ortho-position also required $1 \mathrm{~mol} \%$ of catalyst, but the reaction proceeded smoothly. Encouraged by these and past results with highly hindered substrates, we attempted the addition of 2,6-di-tert-butylphenol (2ao). Unfortunately, this reaction did not proceed at all and only starting materials were observed by GC-FID. These results, in combination with our previous studies [24], where para- $\mathrm{MeO},-\mathrm{CF}_{3},-\mathrm{NO}_{2},-\mathrm{Cl}$ or $-\mathrm{F}$ substituents were also tolerated, support the robustness of our protocol, as it is highly efficient in the presence of a wide range of functional groups.

\section{Polyphenols as nucleophiles}

Intrigued by the versatility of our protocol, we explored the reaction using polyphenols as substrates (Scheme 3 ). Interestingly, we were able to selectively functionalize one (3ap) or both (4ap) hydroxy groups of catechol (2p) by using one or two equiv of 1a, respectively. Unfortunately, for the other polyphenol derivatives only the difunctionalised products could be observed (4aq-4as). We hypothesize that this difference in reactivity may be due to the steric hindrance around the monofunctionalised product 3ap, allowing for a significant rate difference in the reactions of 3ap and 4ap. In other cases, the greater separation between the hydroxy functional groups likely reduces this difference. To put these results in context, the pre-

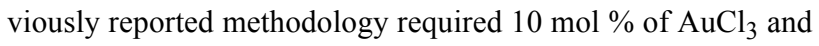
Scheme 1: Dual-gold-catalysed hydrophenoxylation of alkynes. 


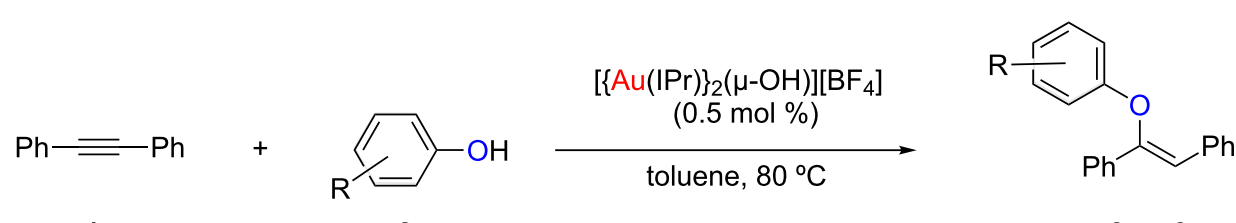<smiles>N#Cc1ccc(O/C(=C\c2ccccc2)c2ccccc2)cc1</smiles>

$3 a a, 50 \%, 24 h^{a}$<smiles>C(=C(Oc1ccc2c(c1)OCO2)c1ccccc1)c1ccccc1</smiles>

3ae, $94 \%, 1 \mathrm{~h}$<smiles>Cc1cc(C)cc(O/C(=C\c2ccccc2)c2ccccc2)c1</smiles>

3ai, 94\%, 2 h<smiles>CC(=O)c1ccc(O/C(=C\c2ccccc2)c2ccccc2)cc1</smiles>

3ab, 90\%, $14 \mathrm{~h}$<smiles>CC(=O)c1ccc(O/C(=C\c2ccccc2)c2ccccc2)cc1</smiles>

$3 a c, 85 \%, 3 \mathrm{~h}$<smiles>O=Cc1ccc(OC(=Cc2ccccc2)c2ccccc2)cc1</smiles>

3ad, 94\%, 6 h<smiles>C(=C(/Oc1ccc2ccccc2c1)c1ccccc1)\c1ccccc1</smiles><smiles>Nc1ccccc1O/C(=C\c1ccccc1)c1ccccc1</smiles>

3ag, 0\%, $24 h^{a, b}$<smiles>Fc1ccc(OC(=Cc2ccccc2)c2ccccc2)c(Cl)c1</smiles>

3ak, 88\%, $6 \mathrm{~h}^{\mathrm{a}}$<smiles>CC1(C)OB(c2ccc(OC(=Cc3ccccc3)c3ccccc3)cc2)OC1(C)C</smiles>

3ah, 0\%, $18 \mathrm{~h}^{\mathrm{a}}$<smiles>Clc1ccccc1O/C(=C\c1ccccc1)c1ccccc1</smiles>

3al, $92 \%, 3 h^{a}$<smiles>C=CCc1ccccc1O/C(=C\c1ccccc1)c1ccccc1</smiles>

3am, $92 \%, 3 h^{a}$<smiles>Cc1cc(O/C(=C\c2ccccc2)c2ccccc2)cc(C)c1Cl</smiles>

3aj, 98\%, $6 \mathrm{~h}$<smiles>CC(C)(C)c1ccc(O/C(=C/c2ccccc2)c2ccccc2)c(C(C)(C)C)c1</smiles>

3an, 83\%, $14 \mathrm{~h}^{\mathrm{a}}$<smiles>CC(C)(C)c1cccc(C(C)(C)C)c1OC(=Cc1ccccc1)c1ccccc1</smiles>

3ao, 0\%, $24 \mathrm{~h}^{\mathrm{a}}$
$96 \mathrm{~h}$ in order to obtain similar yields for $\mathbf{4 a q}[26]$. Moreover, only $7 \%$ of 4 ap could be isolated after $168 \mathrm{~h}[26]$.

\section{Electronic and steric effects on the alkyne}

Next, we sought to assess how the electron density on the alkyne affected the reaction. Therefore, both electron-rich (1) 1e) and electron-poor (1c) alkynes were tested using phenol $2 \mathrm{t}$ as nucleophile. The desired vinyl ethers, 3bt, 3ct and 3et, were obtained in moderate to good yields (Scheme 4). In order to expand the alkyne scope, propargylic ethers were also tested. In this case, 2 equiv of the alkyne were needed to obtain good yields of the desired product, 3dt. Next, we targeted the steric hindrance tolerated around the alkyne. With this aim in mind we decided to use diaryl-substituted alkynes bearing ortho-sub- stituents due to synthetic reasons. The use of the ortho-chlorophenyl derivative $\mathbf{1 f}$ afforded the desired vinyl ether $\mathbf{3} \mathbf{f t}$ in good yields, while changing the chlorides for methyl groups resulted in no reaction, even when using harsher reaction conditions (3gt, Scheme 4). One more highly hindered substrate, $\mathbf{1 h}$, bearing a sterically demanding naphthyl group on one side, and a phenyl on the other was studied. No reaction was observed even after increasing the catalyst loading and temperature (3ht, Scheme 4). Next, we focused our attention on whether the chain length on unsymmetrical alkyl-aryl alkynes, or the electron density on the phenol could affect the regioselectivity of the reaction. The use of 1-phenylbut-1-yne (1i) afforded the desired vinyl ethers 3it and 3it' in a 1:0.23 ratio and in good yields. This selectivity is slightly lower than our previously reported 
<smiles>Oc1ccccc1OC(=Cc1ccccc1)c1ccccc1</smiles>

3ap, $70 \%, 6 \mathrm{~h}^{\mathrm{a}}$

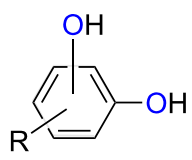

$2 p-s$

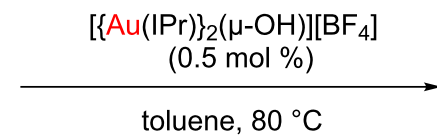

toluene, $80^{\circ} \mathrm{C}$

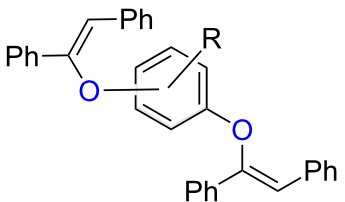

4ap-as toluene $(1 \mathrm{~mL}), 80^{\circ} \mathrm{C}$. Isolated yields, average of two runs. ${ }^{1} 1$ equiv $1 \mathrm{a}$. ${ }^{\mathrm{b}}[\mathrm{Au}](5 \mu \mathrm{mol}, 1 \mathrm{~mol} \%), 110^{\circ} \mathrm{C}$

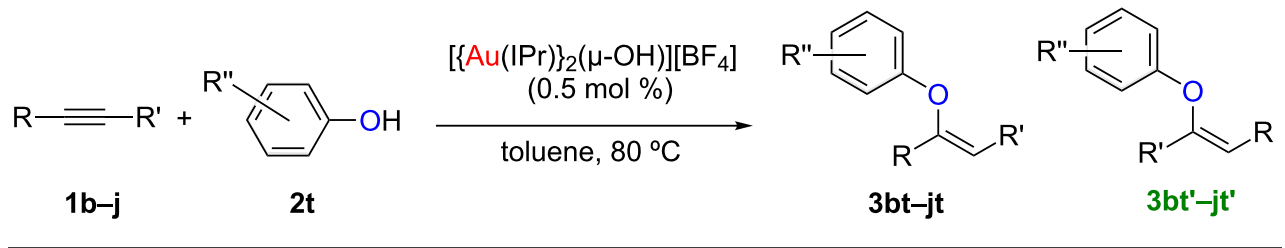<smiles>COc1ccc(/C=C(\Oc2ccccc2)c2ccc(OC)cc2)cc1</smiles>

3bt, $89 \%, 14 h^{a}$<smiles>Clc1ccc(/C=C(\Oc2ccccc2)c2ccc(Cl)cc2)cc1</smiles>

3 ct, $82 \%, 14 h^{a}$<smiles>Cc1ccccc1/C=C(\Oc1ccccc1)c1ccccc1C</smiles>

$3 g t, 0,18 \mathrm{~h}^{\mathrm{a}}$<smiles>COC/C=C(/COC)Oc1ccccc1</smiles>

3dt, $85 \%, 2 \mathrm{~h}^{\mathrm{b}}$<smiles>C(=C(Oc1ccccc1)c1cccs1)c1cccs1</smiles>

3et, $64 \%, 1 \mathrm{~h}^{\text {a }}$<smiles>Clc1ccccc1/C=C(\Oc1ccccc1)c1ccccc1Cl</smiles>

$3 \mathrm{ft}, 87 \%, 6 \mathrm{~h}$<smiles>[R]c1ccc(O/C(C)=C/c2ccccc2)cc1</smiles>

$\mathrm{R}^{\prime \prime}=\mathrm{H}$ 3jt, 90\%, 6 h, 1:0.18

$\mathrm{R}^{\prime \prime}=$ OMe 3ju, 87\%, 6 h, 1:0.22

$\mathrm{R}^{\prime \prime}=\mathrm{NO}_{2}$ 3jv, $90 \%, 6 \mathrm{~h}, 1: 0.35^{\mathrm{a}}$<smiles>C(=C(Oc1ccccc1)c1ccccc1)c1cccc2ccccc12</smiles>

3ht, $0,18 \mathrm{~h}^{\mathrm{a}}$

3it, $80 \%, 6$ h, 1:0.23

Scheme 4: Hydrophenoxylation of (un)symmetrical alkynes. Reaction conditions: 1b-k (0.50 mmol, 1 equiv), $2 t$ ( $0.55 \mathrm{mmol}, 1.1 \mathrm{equiv})$, [Au] $(2.5 \mu \mathrm{mol}, 0.5 \mathrm{~mol} \%)$, toluene $(1 \mathrm{~mL}), 80^{\circ} \mathrm{C}$. Isolated yields, average of two runs. Ratio determined by ${ }^{1} \mathrm{H} \mathrm{NMR}$. a $[\mathrm{Au}](5 \mu \mathrm{mol}, 1 \mathrm{~mol} \%), 110{ }^{\circ} \mathrm{C}$ b $1 \mathrm{~d}$ ( $1 \mathrm{mmol}, 2$ equiv), $2 \mathrm{t}(0.50 \mathrm{mmol}, 1$ equiv). 
hydrophenoxylation of phenylpropyne (1j, 1:0.18) [24]. We also studied if the electron density on the phenol could alter the selectivity. Addition of $p$-methoxyphenol $(\mathbf{2} \mathbf{u})$ to $\mathbf{1} \mathbf{j}$ afforded a 1:0.22 ratio between the two expected products, $\mathbf{3} \mathbf{j u}$ and $\mathbf{3 j u} \mathbf{u}^{\prime}$. This selectivity is slightly diminished compared to the addition of phenol to $\mathbf{1 j}$ (1:0.18), but better than the addition of $p$-nitrophenol (2v, 1:0.35), both reported in our previous study (3jt and 3jv, Scheme 4) [24]. Finally, we tested whether terminal alkynes were tolerated by our methodology. Phenylacetylene (1k) was reacted with phenol (2t) under our standard reaction conditions, $0.5 \mathrm{~mol} \%\left[\{\mathrm{Au}(\mathrm{IPr})\}_{2}(\mu-\mathrm{OH})\right]\left[\mathrm{BF}_{4}\right]$ as catalyst, in toluene at $80^{\circ} \mathrm{C}$ for $1 \mathrm{~h}$. However, GC-FID analysis of the reaction mixture revealed only traces of product. A more careful study of the crude reaction mixture by ${ }^{1} \mathrm{H}$ NMR spectroscopy, revealed $8 \%$ conversion to the desired vinyl ether $\mathbf{3 k t}$, as well as $10 \%$ of acetophenone, the corresponding hydration product. Furthermore, the formation of a new gold species, which was characterised as the previously reported $\sigma, \pi$-digold-acetylide species could also be observed. This diaurated species can be formed by reaction of $\left[\{\mathrm{Au}(\mathrm{IPr})\}_{2}(\mu-\mathrm{OH})\right]\left[\mathrm{BF}_{4}\right]$ with phenylacetylene [30]. As in the case of the formation of a gem-diaurated species when boronic ester $\mathbf{3 h}$ was used, it appears that in situ formation of highly stable diaurated species, inhibits catalytic activity.

These results suggest that while both electron-rich/poor alkynes are tolerated by our methodology, the tolerated steric hindrance is very low, in contrast to the results observed for the nucleophile. In addition, in the case of unsymmetrical alkynes, the use of electron-rich alkynes appears to favour a better selectivity than their electron-poor counterparts.

\section{Enhancing regioselectivity using directing groups}

During our preliminary study on the hydrophenoxylation of unsymmetrical alkynes [24], we observed that the use of alkynes bearing a 2-pyridinyl moiety afforded only one of the possible vinyl ether derivatives (3lt and $\mathbf{3 m t}$, Scheme 5). We hypothesised that this directing effect could be a combination of the charge polarization on the alkyne and an interaction between the pyridine nitrogen and one of the gold centres. To test our hypothesis, we synthesized an alkyne bearing a 3-pyridinyl (1n) substituent. In order to reduce the reaction time the catalyst loading was increased to $3 \mathrm{~mol} \%$. Interestingly, the selectivity dropped dramatically and a 1:0.43 ratio of products was observed (3nt, Scheme 5). In order to further test our hypothesis, the polarization of the alkyne was next reduced, but the potential chelating heteroatom was retained. The hydrophenoxylation of the unsymmetrical propargylic ether 10 afforded, with complete regioselectivity, the corresponding vinyl ether 3ot [32]. As expected, when homopropargylic ether 1p was used diminished selectivity was observed. Thus supporting our hypothesis that regioselectivity can be obtained by assistance of a directing group, either by polarization of the alkyne or by a chelating effect [33].

\section{Conclusion}

We have explored an extended range of reactions in order to fully define the scope and limitations of the digold-mediated hydrophenoxylation of alkynes. With these additions we have performed the gold-catalysed hydroalkoxylation of alkynes on ca. 50 substrates, thus demonstrating the robustness and synthetic versatility of the methodology. The protocol tolerates a wide

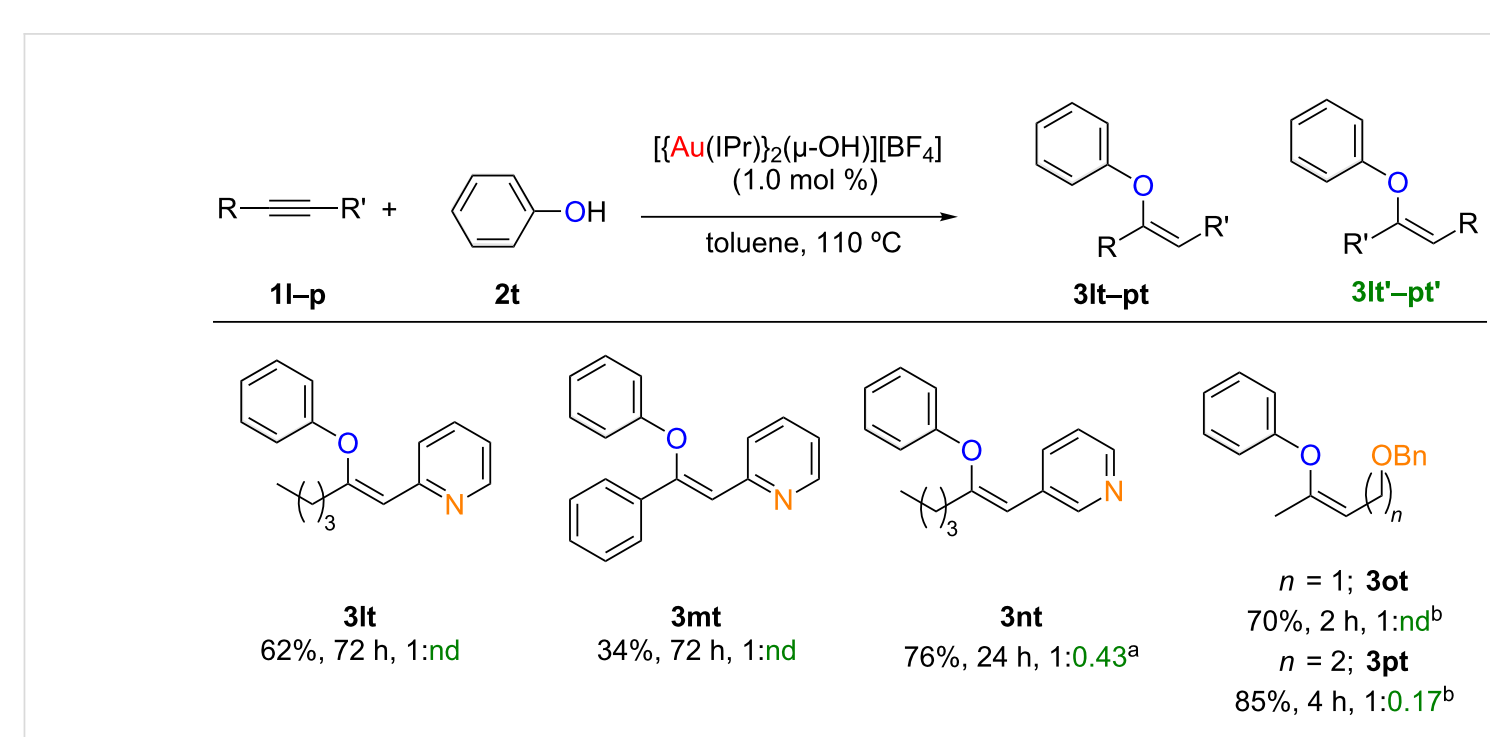

Scheme 5: Regioselective hydrophenoxylation of unsymmetrical alkynes. Reaction conditions: 1I-p (1 equiv), 2 a (1.1 equiv), [Au] (1 mol \%), toluene $(1 \mathrm{~mL}), 110{ }^{\circ} \mathrm{C}$. Isolated yields, average of two runs. Ratio determined by ${ }^{1} \mathrm{H}$ NMR. nd $=$ not detected. ${ }^{\mathrm{a}}[\mathrm{Au}](3 \mathrm{~mol} \%) .{ }^{\mathrm{b}}[\mathrm{Au}](0.5 \mathrm{~mol} \%), 10(2 \mathrm{equiv}$.) 
range of functional groups, such as nitriles, ketones, esters, aldehydes, acetals, naphthyls or allyls. Furthermore, we have successfully used polyphenols in a milder and more efficient manner than the previously reported methodologies. We have also identified that while we are able to use highly steric hindered phenols, small changes on the steric bulk of the alkynes have a dramatic effect on reactivity. More importantly, we have observed that the use of substrates that facilitate the formation of diaurated species such as gem-diaurated or $\sigma, \pi$ digold-acetylide species, hinder the catalytic activity. We have identified that the use of directing groups in unsymmetrical alkynes can help achieve regioselectivity in the hydrophenoxylation reaction. With these studies, we have sought to contribute to a better understanding of the interactions involved in dual-gold-catalysed reactions, and anticipate that this information will help to design more efficient dual-activation protocols. We are currently studying the use of digold-hydroxide species in other dual-gold-catalysed reactions and these results will be published in due course.

\section{Supporting Information}

\section{Supporting Information File 1}

Experimental procedures and characterisation data for all the compounds.

[http://www.beilstein-journals.org/bjoc/content/ supplementary/1860-5397-12-19-S1.pdf]

\section{Acknowledgements}

The ERC (Advanced Investigator Award-FUNCAT) and Syngenta are gratefully acknowledged for support. Umicore AG is acknowledged for their generous gift of materials. This publication is based upon work supported by the King Abdullah University of Science and Technology (KAUST), Office of Sponsored Research (OSR) under Award No. OSR-2015-CCF1974-03. Y.O. thanks the Uehara Memorial Foundation for a Research Fellowship. We also thank Danila Gasperini for early synthetic contributions and Dr. David J. Nelson for helpful discussions.

\section{References}

1. Hopkinson, M. N.; Richter, C.; Schedler, M.; Glorius, F. Nature 2014, 510, 485-496. doi:10.1038/nature13384

2. Nelson, D. J.; Nolan, S. P. Chem. Soc. Rev. 2013, 42, 6723-6753. doi:10.1039/c3cs60146c

3. Díez-González, S.; Nolan, S. P. Coord. Chem. Rev. 2007, 251, 874-883. doi:10.1016/j.ccr.2006.10.004

4. Jacobsen, H.; Correa, A.; Poater, A.; Costabile, C.; Cavallo, L. Coord. Chem. Rev. 2009, 253, 687-703. doi:10.1016/j.ccr.2008.06.006

5. Clavier, H.; Nolan, S. P. Chem. Commun. 2010, 46, 841-861. doi:10.1039/b922984a
6. Dröge, T.; Glorius, F. Angew. Chem., Int. Ed. 2010, 49, 6940-6952. doi:10.1002/anie.201001865

7. Enders, D.; Niemeier, O.; Henseler, A. Chem. Rev. 2007, 107, 5606-5655. doi:10.1021/cr068372z

8. Marion, N.; Díez-González, S.; Nolan, S. P. Angew. Chem., Int. Ed. 2007, 46, 2988-3000. doi:10.1002/anie.200603380

9. Grossmann, A.; Enders, D. Angew. Chem., Int. Ed. 2012, 51, 314-325. doi:10.1002/anie.201105415

10. Díez-González, S.; Marion, N.; Nolan, S. P. Chem. Rev. 2009, 109 3612-3676. doi:10.1021/cr900074m

11. Asay, M.; Jones, C.; Driess, M. Chem. Rev. 2011, 111, 354-396. doi:10.1021/cr100216y

12. Riener, K.; Haslinger, S.; Raba, A.; Högerl, M. P.; Cokoja, M.; Herrmann, W. A.; Kühn, F. E. Chem. Rev. 2014, 114, 5215-5272. doi:10.1021/cr4006439

13. Fortman, G. C.; Nolan, S. P. Chem. Soc. Rev. 2011, 40, 5151-5169. doi:10.1039/c1cs15088j

14. Marion, N.; Díez-González, S.; de Frémont, P.; Noble, A. R.; Nolan, S. P. Angew. Chem., Int. Ed. 2006, 45, 3647-3650. doi:10.1002/anie.200600571

15. Marion, N.; de Frémont, P.; Lemiere, G.; Stevens, E. D.; Fensterbank, L.; Malacria, M.; Nolan, S. P. Chem. Commun. 2006, 2048-2050. doi:10.1039/b602839j

16. Marion, N.; Carlqvist, P.; Gealageas, R.; de Frémont, P.; Maseras, F.; Nolan, S. P. Chem. - Eur. J. 2007, 13, 6437-6451. doi:10.1002/chem.200700134

17. Marion, N.; Gealageas, R.; Nolan, S. P. Org. Lett. 2007, 9, 2653-2656. doi:10.1021/ol070843w

18. Correa, A.; Marion, N.; Fensterbank, L.; Malacria, M.; Nolan, S. P.; Cavallo, L. Angew. Chem., Int. Ed. 2008, 47, 718-721. doi:10.1002/anie.200703769

19. Marion, N.; Ramón, R. S.; Nolan, S. P. J. Am. Chem. Soc. 2008, 131, 448-449. doi:10.1021/ja809403e

20. Ramón, R. S.; Marion, N.; Nolan, S. P. Chem. - Eur. J. 2009, 15 8695-8697. doi:10.1002/chem.200901231

21. Gaillard, S.; Bosson, J.; Ramón, R. S.; Nun, P.; Slawin, A. M. Z.; Nolan, S. P. Chem. - Eur. J. 2010, 16, 13729-13740. doi:10.1002/chem.201001688

22. Nun, P.; Dupuy, S.; Gaillard, S.; Poater, A.; Cavallo, L.; Nolan, S. P. Catal. Sci. Technol. 2011, 1, 58-61. doi:10.1039/c0cy00055h

23. Gómez-Suárez, A.; Gasperini, D.; Vummaleti, S. V. C.; Poater, A.; Cavallo, L.; Nolan, S. P. ACS Catal. 2014, 4, 2701-2705. doi:10.1021/cs500806m

24. Oonishi, Y.; Gómez-Suárez, A.; Martin, A. R.; Nolan, S. P. Angew. Chem., Int. Ed. 2013, 52, 9767-9771. doi:10.1002/anie.201304182

25. Gómez-Suárez, A.; Oonishi, Y.; Martin, A. R.; Vummaleti, S. V. C.; Nelson, D. J.; Cordes, D. B.; Slawin, A. M. Z.; Cavallo, L.; Nolan, S. P.; Poater, A. Chem. - Eur. J. 2016, 22, 1125-1132. doi:10.1002/chem.201503097

26. Kuram, M. R.; Bhanuchandra, M.; Sahoo, A. K. J. Org. Chem. 2010, 75, 2247-2258. doi:10.1021/jo1000143

27. Richard, M. E.; Fraccica, D. V.; Garcia, K. J.; Miller, E. J.; Ciccarelli, R. M.; Holahan, E. C.; Resh, V. L.; Shah, A.; Findeis, P. M.; Stockland, R. A., Jr. Beilstein J. Org. Chem. 2013, 9, 2002-2008. doi:10.3762/bjoc.9.235

28. Oonishi, Y.; Gómez-Suárez, A.; Martin, A. R.; Makida, Y.; Slawin, A. M. Z.; Nolan, S. P. Chem. - Eur. J. 2014, 20, 13507-13510. doi:10.1002/chem.201404630 
29. Dash, C.; Yousufuddin, M.; Cundari, T. R.; Dias, H. V. R.

J. Am. Chem. Soc. 2013, 135, 15479-15488. doi:10.1021/ja406027x

The lack of reactivity observed for $\mathbf{2} \mathbf{h}$ could be due to its reaction with cationic gold, which above $50{ }^{\circ} \mathrm{C}$ can liberate $\mathrm{N}_{2}$ and generate a reactive nitrene species.

30. Gómez-Suárez, A.; Dupuy, S.; Slawin, A. M. Z.; Nolan, S. P Angew. Chem., Int. Ed. 2013, 52, 938-942. doi:10.1002/anie.201208234

31. If these reactions are run under solvent-free conditions, the catalyst loading can be reduced to $0.5 \mathrm{~mol} \%$. For further details see reference [28].

32. Arcadi, A.; Blesi, F.; Cacchi, S.; Fabrizi, G.; Goggiamani, A.; Marinelli, F. Org. Biomol. Chem. 2012, 10, 9700-9708. doi:10.1039/c2ob26763b 2 Equiv of the alkyne were necessary. See for reactions of $1 \mathrm{n}$ under gold catalysis.

33. Gorske, B. C.; Mbofana, C. T.; Miller, S. J. Org. Lett. 2009, 11 4318-4321. doi:10.1021/ol9016782

\section{License and Terms}

This is an Open Access article under the terms of the Creative Commons Attribution License (http://creativecommons.org/licenses/by/2.0), which permits unrestricted use, distribution, and reproduction in any medium, provided the original work is properly cited.

The license is subject to the Beilstein Journal of Organic Chemistry terms and conditions:

(http://www.beilstein-journals.org/bjoc)

The definitive version of this article is the electronic one which can be found at: doi:10.3762/bjoc. 12.19 